\title{
Poemas da Guiana Francesa (Poemas escolhidos de Catacumbas de Sol de Elie Stephenson)
}

\author{
Dennys Silva-Reis ${ }^{1}$
}

Elie Stephenson, nascido em 20 de dezembro de 1944 na Guiana Francesa, é economista e professor na Universidade das Antilhas e da Guiana Francesa, onde preside o CAASSIC ${ }^{2}$ (Centro de Análise Espacial Internacional da América do Sul de Dinâmicas de Desenvolvimento). Influenciado fortemente pela Antillité (Antilhidade) - ideologia que leva em consideração a história e a cultura das Antilhas e que une ao mesmo tempo Créolité et Négritude, bem como os conceitos de mestiçagem, diversidade e ética política e racial (CORZANI, 1998) -, Stephenson escreve sobre a Guiana Francesa não como uma ilha, mas como parte da América do Sul.

Seus escritos potencializam seu horror ao neocolonialismo marcado na Guiana Francesa pelos sistemas franceses DOM e TOM (Departamento e Territórios d'além Mar). Elie Stephenson ao se engajar na literatura é reconhecido como poeta, romancista, contista, dramaturgo e cancionista. Os poemas aqui traduzidos são alguns da compilação de poemas intitulada Catacombes de soleil de 1979. Por questões de espaço, escolhemos traduzir dez poemas que propiciam conhecer de forma direta a realidade do guianense francês e a visão engajada do autor.

O vocabulário que permeia todos os poemas é específico da cultura mestiça crioula-francesa da Guiana Francesa, alguns conseguimos traduzir depois de

\footnotetext{
1 Doutorando em Literatura na Universidade de Brasília (UnB). E-mail: reisdennys@ gmail.com

2 Em francês: Centre d'Analyse Amérique Sud Spatiale Internationale des Dynamiques de Développement.
} 
muita pesquisa - como, por exemplo, eau-debout que é uma adivinhação crioula para cana-de-açúcar -, outros, deixamos como no texto do autor e com uma pequena nota de rodapé para melhor compreensão do leitor.

Houve um pouco de dificuldade no poema homônimo da compilação Catacumbas do Sol porque o autor emprega "amour" no gênero feminino criando um problema para traduzir, pois o uso "amor ensanguentada", por exemplo, poderia soar estranho, bem como soa estranho esse "amour" no feminino em língua francesa, já que seu gênero singular é masculino e pode ser feminino em um uso clássico do plural. Entretanto, optamos por deixar a palavra "amor" e seus adjetivos no gênero masculino já que este não é um recurso essencial na poesia do autor e a fim de não causar tanto estranhamento à primeira vista na leitura poética do apreciador brasileiro. Além disso, ao se referir ao "amor", este, na cultura familiar brasileira, pode tanto ser referido no feminino quanto no masculino independente do gênero dicionarizado da palavra.

Os poemas foram dispostos conforme a publicação do autor que, além de vocabulário e retórica, possui também apresentação gráfica singular que tentamos manter tal qual nos é apresentada e, para tal finalidade, dispomos aqui os poemas um ao lado do outro.

Esperamos que a leitura dos poemas abaixo seja um mergulho na poesia vizinha da Guiana Francesa ainda tão desconhecida no Brasil. 


\section{Poema I}

\section{Limbé $^{3}$ de Cayenne}

La rue marche sans détours toutes les rues sont ainsi chez moi longues allées de cimetière bordées de caveaux-maisons vues du ciel les rues se croisent toutes et chacune à angle droit membres de pierre poutres de fer d'une prison sans barrière

Les rues droites sans point final telles de rigides ascaris

dans les entrailles de la ville plus que jamais solitaire maladive

$$
\text { [et anémique }
$$

les enfants allaient naguère en jouant à «boule au trou » et leurs rires de dahlias nous protégeaient des charognards les rues chaussées de latérite damier de soleil couchant portent aujourd'hui des bas de nuit et sur leur ventre sans nombril déambulent des croque-morts et l'on croirait voir aux feux rouges toujours passer un enterrement.

\section{Agrura de Caiena}

A rua anda sem desvios todas as ruas são assim onde moro longas alas de cemitério bordejadas de túmulos-casas vistas do céu as ruas se cruzam todas e cada uma em ângulo reto membros de pedra vigas de ferro de uma prisão sem grades

As ruas retas sem ponto final como rígidas lombrigas

nas entranhas da cidade mais do que nunca solitária doentia [e anêmica

as crianças iam outrora jogando "bola no buraco" e seus risos de dálias nos protegiam dos urubus as ruas calçadas de laterita tabuleiro de xadrez do sol poente vestem hoje meias de noite e sobre seu ventre sem umbigo passeiam os papa-defuntos e se pensaria ver nos sinais vermelhos sempre passar um enterro.

3 Limbé: grande tristesse, Presque inexprimable. 


\section{Poema II}

\section{MIDI \\ MIDI \\ MIDI}

Vous ne savez pas

La jouissance

de

ce mot

les riches paniers

de

midi .........

midi

transes de madras

les pieds

$$
\begin{aligned}
& \text { nus } \\
& \text { sur }
\end{aligned}
$$

la perle des lances

des barrières-nègres

$$
\text { des }
$$

MIDI

MIDI

MIDI

balafrés d'eaux-debout

coutelas

à entre-ouvrir les cols

de

la morte-violente

des passe-partout

usés

limés

éliminés

Ah !!!!!!

MIDI

MIDI

MIDI

Puissance de ma

TERRE

\author{
MEIO-DIA \\ MEIO-DIA MEIO-DIA \\ MEIO-DIA \\ Você não sabe \\ o gozo \\ desta \\ palavra \\ os ricos cestos \\ de \\ meio-dia . ........ \\ meio-dia \\ transe de madras \\ os pés \\ nus \\ sobre \\ a pérola das lanças \\ das barreiras-negras \\ MEIO-DIA MEIO-DIA \\ MEIO-DIA
}

acutilados de canas-de-açúcar

facão

a entreabrir os colarinhos

da

morte-violenta

chave-mestra

usada

limada

eliminada

Ah !!!!!!

MEIO-DIA

MEIO-DIA

MEIO-DIA

Potência de minha

TERRA 


\section{Poema III}

\section{CARAIBES}

Aquarelles d'îles

je ne connais pas

la lagune de ses cheveux

les auréoles de ses rives et ses cris

de sable précipité d'ébène

ni ses vagues florales

mais je sais

l'obsession qui m'anime

\section{CARAIBES}

Aquarelles d'îles

colonnades de mornes bruissants

à l'appel de sa peau

soleil avant-garde

rivières

de sucre de canne

à sang.

Nous bénirons

l'arbre à pain l'igname et la banane dans les festins populaires

et la danse des terreaux

Caraibes... je ne sais

la saveur de sa sueur

mais j'entends

la famine qui m'anime

\section{CARIBE}

Aquarelas de ilhas

eu não conheço

a laguna de seus cabelos

as auréolas de suas margens e seus gritos

de areia precipitada de ébano

nem suas ondas florais

$$
\text { mas sei }
$$

a obsessão que me anima

\section{CARIBE}

Aquarelas de ilhas

colunatas de montanhas ruidosas

ao chamado de sua pele

sol vanguarda

rios

de açúcar de cana

de sangue.

Abençoaremos

a fruta-pão o inhame e a banana

nas festas populares

e a dança dos terreiros...

Caribe... eu não sei

o sabor de seu suor

mas eu ouço

a fome que me anima

\section{CARAIBES}

\section{CARIBE}

Fort-de-Fance

Cayenne

1976
Forte de França

Caiena

1976 


\section{Poema IV}

\section{SAISONS}

Il y a toujours eu

trop de pluies... trop de pluies

trop de pluies

trop de larmes et de prières

alors nous avons pris

l'habitude d'aller

toujours tête baissée

dos voûté

reins cassés

Oh ! non ce n'est pas

que j'abhorre le soleil

le soleil

et les fleurs

les fleurs

et les insectes

les hommes

et les hyènes

les hyènes

et les papillons

Oh! non

ce n'est pas

que je veuille chanter

crier

revendiquer

exhorter

attaquer

Oh! non

ce n'est pas

que j'exige le sang

LE SANG

LE SANG !

mais

je n'aime pas

qu'on me parle d'un trône

je n'aime pas

qu'on m'édicte

me décrète

\section{ESTAÇÕES}

Sempre houve

chuvas demais... chuvas demais

chuvas demais

lágrimas e orações demais

adquirimos então

o hábito de andar

sempre de cabeça baixa

costas curvadas

espinhela caída

Oh! Não não é

que eu abomine o sol

o sol

e as flores

as flores

e os insetos

os homens

e as hienas

as hienas

e as borboletas

Oh! não

não é

que eu queira cantar

gritar

reivindicar

exortar

atacar

Oh! Não

não é

que eu exija o sangue

O SANGUE

O SANGUE!

mas

eu não gosto

que me falem de um trono

eu não gosto

que me sancionem

me decretem 
m'enseigne

m'assimile

m'instruit

me détruit

non!

non!

Je n'aime pas

qu'on me cajole

m'infantilise

me soudoie

me menace

qu'on m'importe

m'exporte

me gave et m'affame

Je ne supporte pas

qu'on DISPOSE de

MOI

de ma Terre

de mon peuple! me ensinem

me assimilem

me instruam

me destruam

não!

não!

Eu não gosto

que me mimem

me infantilizem

me comprem

me ameacem

que me importem

me exportem

me engordem e me esfomeiem

Eu não suporto

Que DISPONHAM de

MIM

de minha Terra

de meu povo 


\section{Poema V}

\section{CAYENNE}

Cayenne

un nom machinal étendu entre mes

[lèvres

harassées de secousses exfoliées

un rappel de cris encerclés par une

[mutilation

de membres annexes

où s'exhibe ma solitude décharnée

\section{Cayenne}

une violence de prunelles désorientées

un clapotis de pieds tawa

dans les rios tapis

de sang

quand nos révoltes s'éveillent en

de beaux rêves réparateurs

ma solitude est un cauchemar

\section{CAIENA}

Caiena

um nome maquinal estendido entre meu

|lábios

cansados de abalos esfoliados

uma lembrança de gritos rodeados por uma

de membros anexos

[mutilação

onde se exibe minha solidão descarnada

Caiena

uma fúria de pupilas desorientadas

um marulho de pés tawa ${ }^{4}$

nos rios emboscados

de sangue

quando nossas revoltas despertam em

belos sonhos reparadores

minha solidão é um pesadelo

$$
\begin{aligned}
& \text { denunciar o suicídio? } \\
& \text { denunciar o crime? } \\
& \text { a tirania? } \\
& \text { a assimilação? } \\
& \quad \text { denunciar? }
\end{aligned}
$$

\section{Caiena}

uma obstinação de coleópteros em volta de plantações de barriga-vazias e de peixes magros de nossas gengivas uma exaltação de pimenta pungente sobre

feridas atentas ao barulho ao movimento

às cores a toda revolta a todo abalo

aux couleurs à toute révolte à toute

[secousse

viendrez-vous, vous mirer autour de

[ces étangs virão os senhores, contemplar-se em torno

[desses tanques

4 "Amarelo" na língua oiampi, falada pelos índios na Guiana francesa (GRENARD, 1989). 
viendrez-vous y boire

et pétrir notre Foi ?

Je ne sais pourquoi le ciel a la gueule

[écrabouillée

je ne sais pourquoi les oiseaux sont

[aphones et revanchards

je ne sais pourquoi les déserts ont

[pénétré les pinotières

ni pourquoi les chiens palabrent et

[pourquoi

les pucerons ont pris la direction des

[affaires

mais je vis à Cayenne

et je vais en mourir.

16 mai 1975 virão os senhores aí beber

e moldar nossa Fé?

Eu não sei por quê o céu tem a cara

[espatifada

não sei por quê os pássaros são

[afônicos e vingativos

não sei por quê os desertos

[penetraram as pinotières ${ }^{5}$

nem por quê os cães tagarelam e

[por quê

os pulgões assumiram a direção dos

[negócios

mas eu vivo em Caiena

e vou dela morrer.

16 de maio de 1975

5 Nome dado à savana típica da Guiana Francesa. 


\section{Poema VI}

\section{TERRE-VIE}

Là-bas près de la crique où la vie s'est faite terre il y a un carbet tout se ressemble

L’aïeule ridée tassée labourée tronc frêle de manioc que plantent heureusement les enfants de ses enfants Là-bas près de la crique où la vie s'est faite terre l'homme compte les jours :

fruits

légumes boucanes

quand les pluies sont trop longues

la terre a trop froid

il se couche sur elle la réchauffe et l'anime

Là-bas près de la crique où la vie s'est faite terre il y a mon cœur un carbet

mon enfance... une jeune négresse tout lui ressemble l'arcade des arbres les algues du feu Là-bas près de la crique où l'amour s'est faite terre.

\section{TERRA-VIDA}

Lá perto da enseada onde a vida se fez terra tem um carbeto tudo se parece

A avó enrugada amontoada escalavrada tronco frágil de mandioca que os filhos de seus filhos plantam com alegria Lá perto da enseada onde a vida se fez terra o homem conta os dias:

frutos

legumes moquéns

quando as chuvas demoram demais a terra tem muito frio ele se deita sobre ela a aquece e a anima

Lá perto da enseada Onde a vida se fez terra tem meu coração um carbeto ${ }^{6}$

minha infância...

uma jovem negra tudo se parece com ela a arcada das árvores as algas do fogo Lá perto da enseada onde o amor se fez terra.

6 Segundo o dicionário em sua primeira acepção: Carbeto é entre os indígenas, grande casa de reuniões. 


\section{Poema VII}

CATACOMBES de SOLEIL

L'obsédante amour

ensanglantée d'un pleur

coutelas de solstices

ah ! jeunesse égarée

dans les quinconces

dans les vérités de cadavres.

L'obsédante amour

hostile à toute reddition

et à toute compromission

poteau-mitan de trois siècles

patinés rebutés abusés

et les foules d'invocation

clapotis informes

au carrefour de ses yeux

défilent ainsi des étoiles sans orbite.

Sur les contreforts d'échardes

Ah... cette obsédante amour

dans la bouche ne se lasse

et le cœur ne se libère

mutinerie de la Légende

rendue folle de décrets

j'en suis et jusqu'à la mort

de toute joie Hors-la-Loi

il y a trop d'assassins qui se baladent

dans les bibles

il vaut mieux chevaucher

un chien

qu'embrasser un « politicien »

pourquoi ne pas laisser aux singes

les parlements et les tribunes

ils occuperaient mieux la place!
CATACUMBAS de SOL

O obsedante amor

ensanguentado de um choro

facão de solstícios

Ah! juventude extraviada

nos quincunces

nas verdades de cadáveres

O obsedante amor

hostil a toda rendição

e a todo comprometimento

poteau-mitan ${ }^{7}$ de três séculos

patinados rejeitados abusados

e as multidões da invocação

marulhos informes

no cruzamento de seus olhos

desfilam assim estrelas sem órbita.

Sobre os contrafortes de espinhos

Ah... este obsedante amor

$\mathrm{Na}$ boca não se cansa

E o coração não se libera

motim da Legenda

tornada louca de decretos

por ele sou e até a morte

com toda alegria Fora da lei

há assassinos demais que passeiam

nas bíblias

é melhor cavalgar

um cachorro

que abraçar um "político"

por que não deixar aos macacos

os parlamentos e as tribunas

eles ocupariam melhor o lugar!

7 Poteau-mitan é a versão francesa da expressão antilhana potomitan que designa o pilar central no templo de vodu. A expressão igualmente pode qualificar o arrimo de família, geralmente, a mãe. O termo pode se referir àquele/àquela que está no centro do lar, o individuo em torno do qual tudo se organiza e se apoia. 
O cette obsédante amour catacombes de soleil l'oppression est légitime tu ris et ne m'embrasses pas tu passes et ne me frôles pas ô cette obsédante amour et j'en suis jusqu'à la Vie de toute joie excommuniée.
Oh este obsedante amor

catacumbas de sol

a opressão é legítima

tu ris e não me abraças

passas e não me afagas

Oh este obsedante amor

e por ele sou até a Vida

com toda alegria excomungada. 


\section{Poema VIII}

\section{MEMOIRE}

J'aime ce souvenir

du plus haut des balcons

tranches de ciel que lissait son regard

robes de jeunes-filles... nuages sensuels

visage illimité

à court de paraboles ;

j’aime ce souvenir

de figures naïves

du soleil et des brûlis

qui ne t'ont jamais trahie

ni dérobé ton bel amour.

Je ne sais où j'ai chanté

où j'ai couru

où j'ai pleuré

la mer le vent et la pluie

et le soleil et les saisons

partagent l'année en deux

une partie nourrit mon cœur

l'autre affame ma mémoire...

Je ne vois que trahison

je ne vois que négation

je ne vois que dérision

où l'amour n'est plus mirage

fantaisie livre d'images

négation exploration.

J'aime ce souvenir du plus haut

des balcons

en la plaine digitale

où s'esclaffaient nos baisers

(sans demain et sans hier)

parler m'en sans arrêt

même si tu te tais.

\section{MEMÓRIA}

Amo esta lembrança

da mais alta das sacadas

fatias de céu que seu olhar alisava

vestidos de meninas... nuvens sensuais

face ilimitada

na falta de parábolas;

amo esta lembrança

de figuras inocentes

do sol e das queimaduras

que nunca te traíram

nem ocultaram teu belo amor.

Eu não sei onde cantei

onde corri

onde chorei

o mar o vento e a chuva

e o sol e as estações

dividem o ano em dois

uma parte alimenta meu coração

a outra esfomeia minha memória...

Eu só vejo traição

só vejo negação

só vejo irrisão

onde o amor não é mais miragem

fantasia livre de imagens

negação exploração.

Amo esta lembrança da mais alta

das sacadas

na planície digital

onde gargalham nossos beijos

(sem amanhã e sem ontem)

fale-me disso sem parar

mesmo se você se calar 


\section{Poema IX}

\section{UN MOT}

Un mot

et la peur

Un geste

et la peur

Un rire

et la peur

Un oubli

un regard

un baiser

une danse

une chanson

L'infini des mouvements

des enlacements

des ballets

du corps... du cœur

et la Peur

depuis l'enfance

creusée en Nous

et parce que nous avons Peur

nous sommes toujours

Prêts

à détruire en nous-mêmes

l'ombre du Merveilleux.

\section{UMA PALAVRA}

Uma palavra

e o medo

Um gesto

e o medo

$\mathrm{Um}$ riso

e o medo

Um esquecimento

e o olhar

um beijo

uma dança

uma canção

O infinito dos movimentos

dos abraços

dos balés

do corpo... do coração

e do Medo

desde a infância

escavado em Nós

e porque nós temos Medo

nós estamos sempre

Preparados

para destruir em nós mesmos

a sombra do Maravilhoso. 


\section{Poema X}

Pour Bebé et Bertène
affectueusement.

Je parle de REVOLUTIONS!

Tous les dieux sont parmi Nous

comme il fallait s'en souvenir

imagerie de cimetière

un beau fléau venu du ciel

à l'assaut des bouches Nouvelles.

Que le peuple élève son pas au-dessus

de cascades calcinées.

[des catafalques

Je parle de Révolutions

exubérant aux portes des ventres rebelles je parle de Révolutions tangibles

collectives et personnelles, [et invisibles

toutes plantes ébouriffées

la pluie brille à notre infini éclaté

des marées virginales,

les fleurs n'iront plus à l'autel au tombeau

ni dans les vases, sur la poitrine des

[citoyennes

et la semelle des statues.

Nous conjuguerons nos yeux

où les Hommes ne mourront pas

— vaisseaux lancés sur les récifs

pas de distants capitaines -

nous serons, un maintenant maintenu [sans désunion

ô Femmes qui serez hommes hommes qui serez enfants enfants qui serez racines feuillage et

\section{TOUS}

[paysage

au-delà de la muraille la rocaille et

[la mitraille

nous camperons l'air en plein et rien

[n'abaissera
Para Bebé Bertène

Afetuosamente.

Eu falo de REVOLUÇÕES!

Todos os deuses estão entre Nós

como é preciso recordar

imagens de cemitério

uma bela praga vinda do céu

ao assalto das bocas Novas.

Que o povo erga seu passo acima dos

[catafalcos

de cachoeiras calcinadas.

Eu falo de Revoluções

exuberante às portas dos ventres rebeldes

Falo de Revoluções tangíveis e invisíveis

coletivas e pessoais, todas as plantas desgrenhadas

a chuva brilha em nosso infinito explodido de marés virginais,

as flores não irão mais ao altar à tumba

nem nos vasos, sobre o peito das

[cidadãs

e a sola das estátuas.

Nós conjugaremos nossos olhos

onde os Homens não morrerão

— navios lançados sobre os recifes

pelos distantes capitães -

nós seremos, um agora mantido

[sem desunião

ó Mulheres que serão homens

homens que serão crianças

crianças que serão raízes folhagem e

[paisagem

\section{TODOS}

além da muralha da rocalha $\mathrm{e}$

[da metralha

acamparemos ao ar livre e nada abaixará 
nos bras et rien ne fléchira nos fronts, [rien ne troublera nos yeux et nos lèvres et nos cœurs...

Je parle de REVOLUTIONS qui se [feront et qui vivront.

Décembre 1977. nossos braços e nada dobrará nossas

[frontes, nada perturbará

nossos olhos e nossos lábios e nossos

Eu falo de REVOLUÇÕES que se

[corações...

[farão e que viverão.

Dezembro 1977.

\section{Referências bibliográficas}

GRENAND, F. Dictionnaire wayãpi-français. Peeters Publishers: Leuven, 1989.

STEPHENSON, E. Catacombes de soleil. Paris: Éditions Caribéennes, 1979.

CORZANI, Jack. "Antilles-Guyane”. In: . et alii. Littérature francofones II - Les Amériques: Haïti, Antilles-Guyane, Québec. Paris: Belin, 1998. 